\title{
Stability Problems of Compressed Thin-Walled Structures
}

\author{
Hubert Debski ${ }^{1}$ \\ 1 Department of Machine Design and Mechatronics, Lublin University of Technology, Lublin, Poland, \\ e-mail: h.debski@pollub.pl
}

\begin{abstract}
The object of this study involves thin-walled columns made of carbon-epoxy composite with open top-hat crosssection. The material used comprised a composite of epoxy matrix reinforced with carbon fiber (system HexPly M12, Hexcel). The M12 system is used above all in aircraft structures. It exhibits high fatigue durability and good maintenance properties at relatively low specific gravity. The research was carried out as the FEM numerical analyses and experimental tests in buckling and post-buckling state. The numerical tool used was the ABAQUS software.
\end{abstract}

Keywords: thin-walled columns, composite structures, buckling, finite element modelling,

\section{INTRODUCTION}

Polymeric composites - laminates - are currently one of the most rapidly developing groups of materials applied in contemporary thin-walled structures. This is connected with an advantageous set of physicochemical and mechanical properties, particularly high strength in relation to low mass density of the composite material $[1,2]$. From a wide group of laminates mainly those having epoxy matrix reinforced with glass, carbon or kevlar fibers, find applications. Exceptionally advantageous strength characteristics of a laminate can be obtained by utilization of advanced forming techniques of polymeric composites, such as autoclaving [3].

In the design process of complex composite materials an important role is played by a sequence of plies, having a decisive influence on load carrying abilities of particular components of the stress state. This applies to thin-walled composite structures stability as well, in which a specific ply sequence can have an essential influence on a value of critical load or a structure's stiffness in the post-critical state [4-9].

In this work, the results of experimental tests on thin-walled composite columns of top-hat cross-section subjected to compressive load were presented. The obtained research results enable to verify the results given by FE models, as well as by author's own analytical-numerical (ANM) method based on the Koiter theory [10]. The experiments also covered determination of material properties, used later in the worked out numerical models. Such approach allowed more credible comparison of the prepared composite profiles behaviour with numerical models, being usually only models of ideal structures.

\section{OBJECT OF RESEARCH}

The object of the research was the thin-walled beam made of carbon-epoxy composite formed into a top-hat cross-section with the following dimensions: $80 \times 40 \times 1.048 \mathrm{~mm}$ (the cross-section) and $\mathrm{L}=300 \mathrm{~mm}$ (the length) - Fig. 1 .

The composite had epoxy matrix having the following characteristics: mass density: $1.24 \mathrm{~g} / \mathrm{cm}^{3}$; curing temperature: $128^{\circ} \mathrm{C}$; tensile strength: $64 \mathrm{MPa}$; Poisson ratio: 0.4; Young modulus in tension: 5.1 GPa. The AS7J12K carbon fibres were used for reinforcement, with mass density: $2.5 \mathrm{~g} / \mathrm{cm}^{3}$; tensile strength: $4830 \mathrm{MPa}$; 
Poisson ratio: 0.269; Young modulus in tension: $241 \mathrm{GPa}$. Nominal volume fraction of the reinforcement was approximately equal to $60 \%$.

The following mechanical characteristics were determined experimentally for the used composite pre-pregs, according to the ISO standard: Young moduli: $E_{1}=130.71 \mathrm{GPa}, E_{2}=6.36 \mathrm{GPa}$, Kirchhoff modulus: $G_{12}=4.18 \mathrm{GPa}$, Poisson ratio: $v_{12}=0.32$. The experimentally determined strength characteristics of the carbon-epoxy composite were exploited in the definition of material model in the FEM calculations.

Two types of 8-ply composite columns were tested. The layups were symmetrical, as follows: (a) $-[90 / 45 /-45 / 0]_{\text {s }}$ and (b) $-[45 /-45 / 90 / 0]_{\text {s. }}$ Each ply had the same thickness of $0.131 \mathrm{~mm}$. In Fig. 2 the used ply sequence was given.

\section{EXPERIMENTAL INVESTIGATION}

The experimental tests were conducted on axially compressed thin-walled composite columns with top-hat cross-section. Stand tests were performed with the Zwick Z100/SN3A 1-accuracy class universal testing machine of the $100 \mathrm{kN}$ load range - Fig.3. Any imperfections of the column ends, capable of causing unwanted boundary effects, were compensated by specially prepared soft-plastic pads. Before each test, the loading system was loaded up to $15 \%$ of the expected critical load in order to provide best alignment of the column placed between the grips. Next, the grip retainers were removed and the column was completely unloaded. Vishay's electrical strain gauges were stuck along the loading direction on

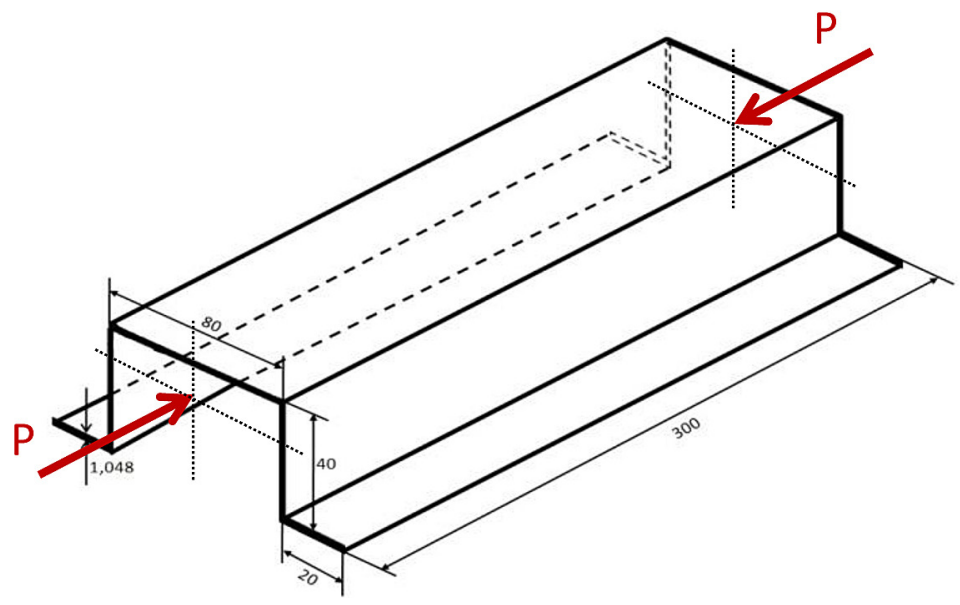

Fig. 1. Dimension of the analyzed columns

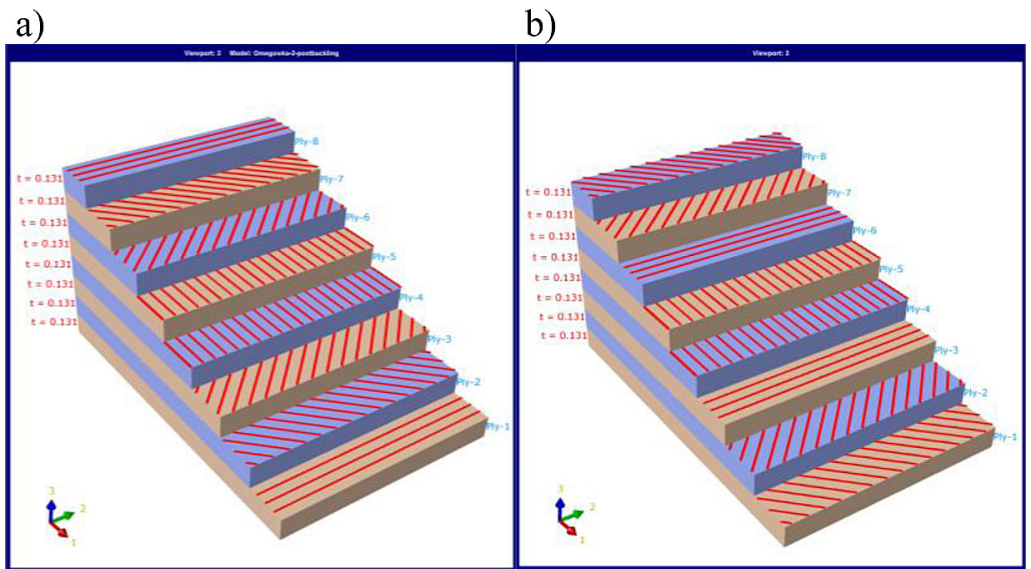

Fig. 2. Layup arrangement used in the research: a) $[90 / 45 /-45 / 0]_{\mathrm{s}}$, b) $[45 /-45 / 90 / 0]_{\mathrm{s}}$ 


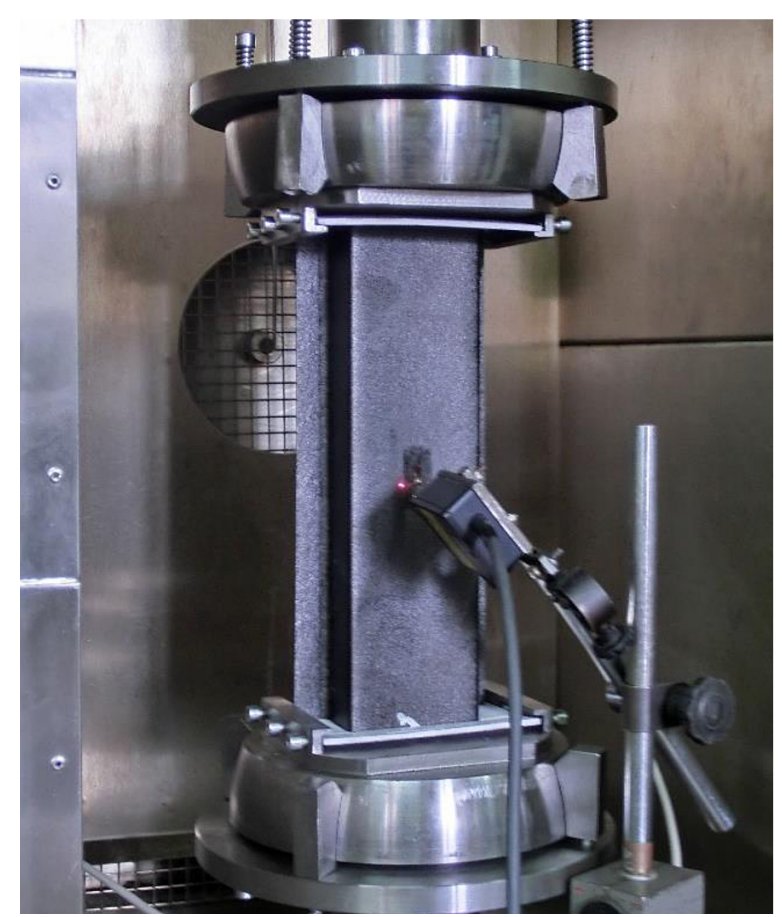

Fig. 3. The test stand with a composite sample

the specimen's internal and external surfaces in the vicinity of the largest web's deflection area,. The two CEA-06-125UW-350 series gauges had a constant $\mathrm{k}=2.135 \pm 0.5 \%$ and electrical resistance of $350 \Omega \pm 0.3 \%$. In addition, the deflections were measured with the optoNCDT 1605 laser dilatometer. All the measurement elements were plugged to the MGCplus system (Hottinger). During the tests the indications of all sensors were registered with a frequency of $1 \mathrm{~Hz}$.

All tests were conducted under standard conditions, at $23^{\circ} \mathrm{C}$ with constant velocity of the cross-bar equal to $2 \mathrm{~mm} / \mathrm{min}$. The experiments were carried out in sub-critical range with registration of parameters needed in determination of critical loads, as well as in post-critical range. For each of the considered ply sequences three samples were tested and the measurements were performed thrice. Thus, nine measurements were performed for each layup in order to determine the sub- and post-critical characteristics of columns.

\section{EXPERIMENTAL METHODS FOR BUCKLING LOADS DETERMINATION}

On the basis of the obtained experimental results, the values of critical load were determined, in accordance with the following methods:

a) the vertical-tangent line method (the meanstrains method)-denoted as K1 [11,12,13], b) the method of straight lines intersection in the plot of mean strains - denoted as K2 [11,12,13],

c) the $\mathrm{P}-\mathrm{w}^{2}$ method - denoted as $\mathrm{K} 3[11,12,13]$,

d) the inflexion-point method - denoted as K4 [12],

e) the Tereszowski method - denoted as K5 [14],

f) he Koiter method - denoted as K6 [5,15].

The methods for the critical load determination employed in the conducted research demand approximative calculations based on the results of experimental measurements. The computations performed in such a way aimed at matching the functions describing the analyzed phenomena with the experimental outcomes. Note that an appropriate choice of measurement points from all the accessible data was crucial and decisive for the final results of calculations. It was connected to an idea of the so-called pivotal points elaborated by Bronshtein and Semendyayev [16] and implemented by Spencer and Walker [17] in an analysis of experimental results for plates. This idea states that an appropriate choice of the pivotal points leads to sufficiently optimal matching of the analyzed function to experimental data.

The exemplary results of deflection $w$ and strains $\varepsilon$ measurements for the [90/45/-45/0 $]_{\mathrm{s}}$-sequence column are presented in Figs 4-6. The elaborated relations between the displacements or the strains and the external load enabled the determination of the critical load with the methods $\mathrm{K} 1-\mathrm{K} 3$, whereas the values of the critical load determined with the methods K4 - K6 were obtained numerically.

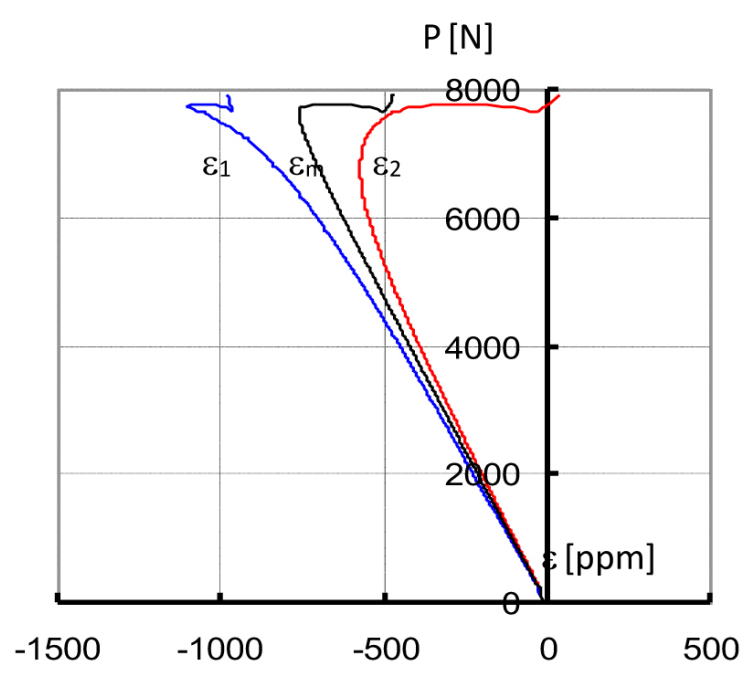

Fig. 4. Dependence of compression load on deformations $\varepsilon_{1}, \varepsilon_{2}$ and $\varepsilon_{m}=0.5\left(\mathrm{e}_{1}+\mathrm{e}_{2}\right)-$ the mean-strains method (K1) 


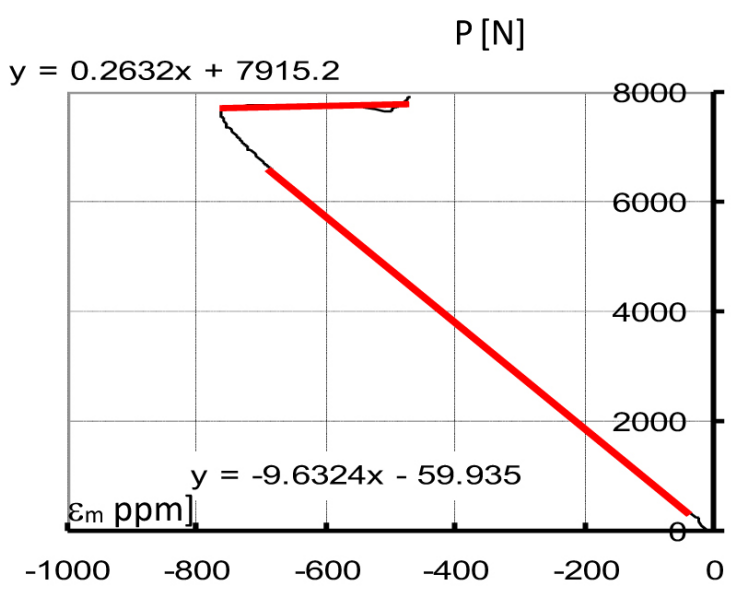

Fig. 5. Dependence of compression load on deformations $\varepsilon_{m}=0.5\left(\mathrm{e}_{1}+\mathrm{e}_{2}\right)$ - the method of straight lines intersection in the plot of mean strains (K2)

\section{NUMERICAL CALCULATIONS}

The finite element method and analytical-numerical method were employed to buckling analysis and post buckling behaviour of thin-walled composite columns. Two different software packages (ABAQUS $\AA$ and ANSYS $\AA$ ) were used for numerical calculation. They were thin-walled plane-stress shell elements with 8 nodes (S8R in ABAQUS ${ }^{\circledR}$ and SHELL 99 - in ANSYS $\left.{ }^{\circledR}\right)$. Both used elements have six degree of freedom at each node. A Layup-Ply technique was employed for the purpose of the symmetrical laminate modelling. A numerical model of the top-hat section composite columns is presented in Fig.7.

The boundary conditions of the numerical model representing articulated support of the column ends were defined by restraining the kinematic degrees of freedom of the nodes belonging to the borders of the first and the last cross-section. The load was applied to the model as uniformly distributed concentrated forces at the top-end of the column (Fig.7).

The properties of composite material were described by definition of orthotropic material in plane stress state, which allowed to describe the laminate properties in particular directions, according to the arrangement of fibres. The numerical calculations within the framework of FE were performed in two stages. The linear stability problem (critical state) was solved by finding critical load and buckling mode, as well. Verification of the obtained results was performed with the ANM method [18], based on the Koiter's general asymptotic theory of conservative systems stability [5]. In Figures 8 and 9 the lowest buckling modes

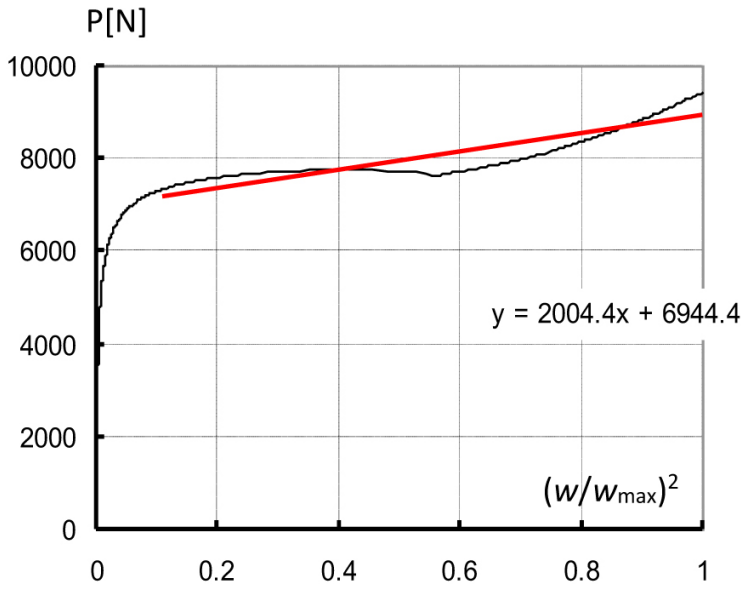

Fig. 6. Dependence of compression load on square dimensionless deflection $\mathrm{w}^{2}=\left(\mathrm{w} / \mathrm{w}_{\max }\right)^{2}(\mathrm{~K} 3)$

of the analyzed columns obtained numerically were presented in comparison with experimental outcomes. The obtained buckling modes exhibited different numbers of the half-waves along the symmetry axis of the column, depending on the layup - the [90/45/-45/0]-sequence column had 7 halfwaves, whereas the $[45 /-45 / 90 / 0]_{s}$ one 5 halfwaves. The critical load values determined with the methods K1 - K6 using the experimental results were compared with the numerical, as well as the analytical-numerical results - see Figures 10 and 11.

The post-critical calculations were performed as non-linear static analysis of the structure with initiated imperfections having a dimension of 0.1 of the top-hat profile wall thickness, corresponding to the first instability mode of the column.

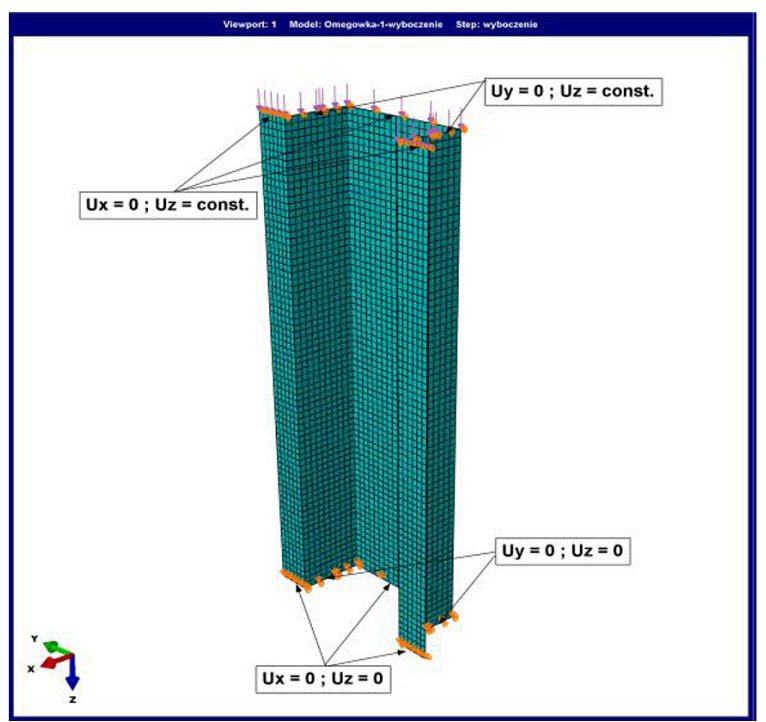

Fig. 7. FEM model of composite column 

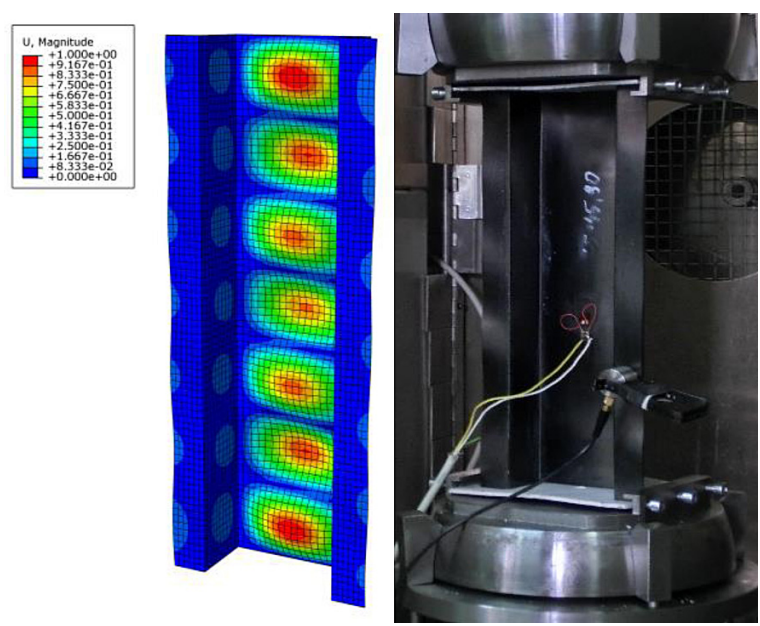

Fig. 8. Buckling mode of the $[90 / 45 /-45 / 0]_{\mathrm{s}}$ - sequence column

The post-critical analysis taking into account geometrically non-linear problem in ABAQUS was performed with incremental-iterative NewtonRaphson method, whereas the post-critical equilibrium path was tracked with the Arc-length procedure (the Ricks Method) in the Ansys program. The range of the numerical calculations also covered an attempt to estimate a probability of the composite damage occurence in post-critical state according to the Tsai-Wu criterion [19-22].

The postcritical force-deflection $(P-w)$ equilibrium paths calculated numerically up to ca. $150 \%$ of the critical load were compared with experimental results - Figures 12 and 13.

Post-critical range analysis enabled to assess the deformation and the stiffness of the structure after the stability loss in relation to the ply sequence of the laminate. The experimental tests were performed within the range exceeding the critical forces values obtained numerically with the FEM by ca. 1.5-times. An attempt was made to assess the failure load value in accordance with the Tsai-Wu criterion $[19,20]$. In Fig. 14,
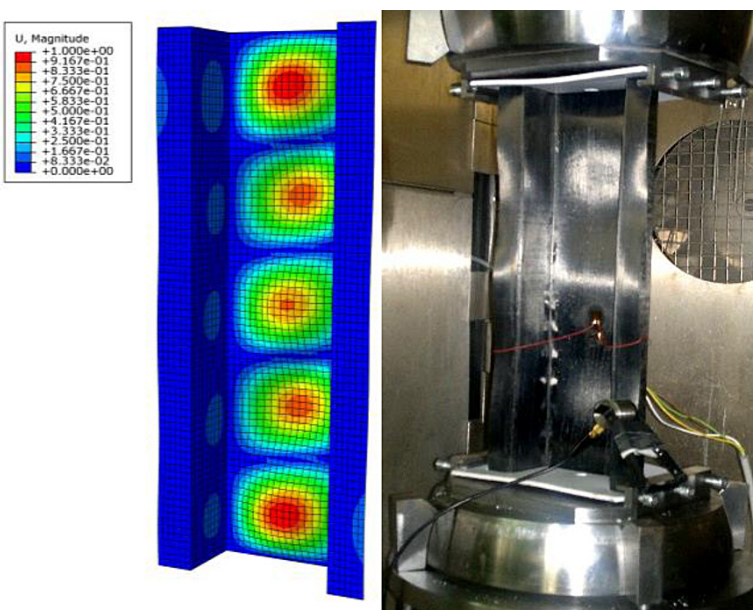

Fig. 9. Buckling mode of the $[45 /-45 / 90 / 0]_{\mathrm{s}}$ - sequence column

the post-critical deformation of the compressed columns corresponding to the failure load value was presented (the Tsai-Wu-criterion failure parameter equal to 1$)$.

\section{COMPARISON OF THE RESULTS}

The analysis of the critical state outcomes for the compressed composite columns shows a complete qualitative agreement of the buckling modes obtained with each of the exploited methods (FEM, ANM and the experiments). In each case, the same number of half-waves along the axis direction of the column was obtained, which characterized the structure buckling mode for the lowest value of the critical load. High conformity of the results was observed also for the value of the critical load determined numerically (with ABAQUS, ANSYS and ANM) with the experimental results obtained with the methods K1 - K6 (Figures 10 and 11). The quantitative analysis of the critical load values exhibited maximal

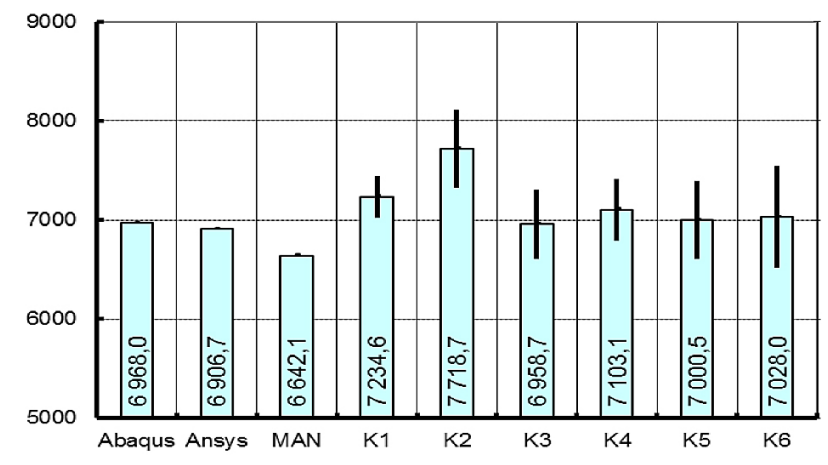

Fig. 10. Critical load values for the $[90 / 45 /-45 / 0]_{s}$-sequence column 


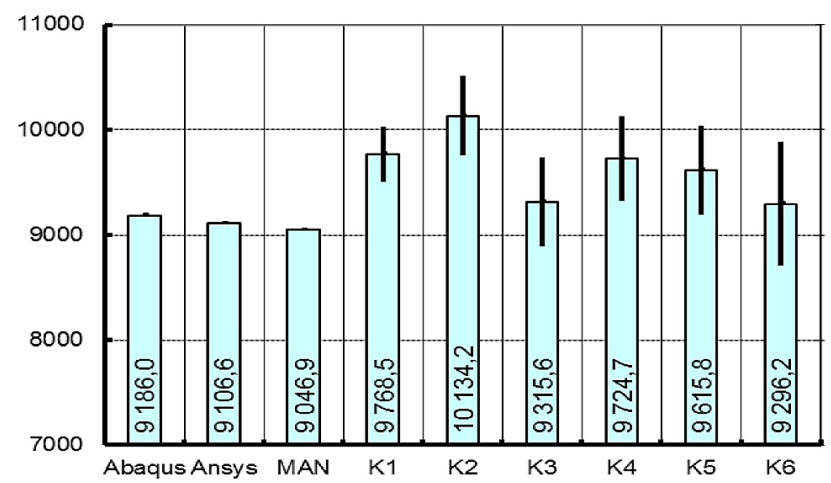

Fig. 11. Critical load values for the $[45 /-45 / 90 / 0]_{\mathrm{s}}$ - sequence column

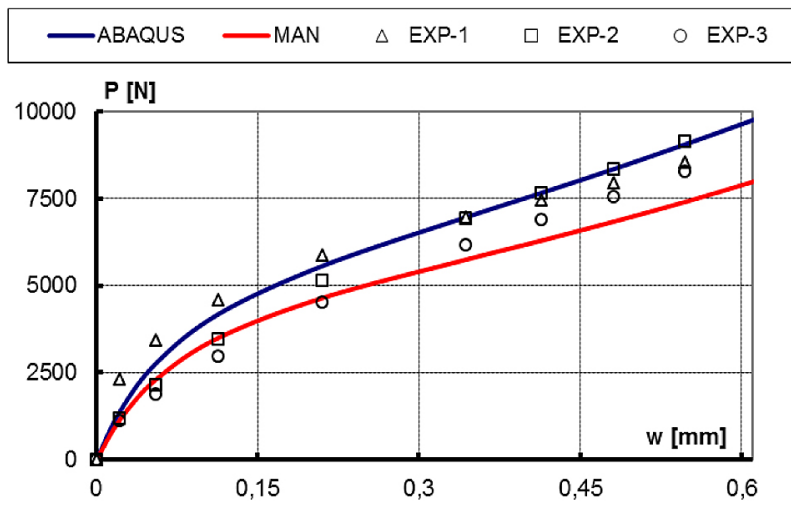

Fig.12. Comparison of post-buckling paths obtained numerically with experimental results for the $[90 / 45 /-45 / 0]_{\mathrm{s}}-$ sequence column

discrepancies of the obtained results for the ANM and K2 methods: $13.9 \%$ for the column with the $[90 / 45 /-45 / 0]_{\mathrm{s}}$ ply sequence and $10.7 \%$ for the $[45 /-45 / 90 / 0]_{\mathrm{s}}$ one. Rejection of the extreme values determined experimentaly allowed to decrease the discrepancy below $10 \%$, which meant high compatibility of the results in the case of the structure stability research. The discrepancy of the numerical results did not exceed $5 \%$.
The obtained results enabled to assess the influence of the sequence of plies on the value of the critical load. It was observed that moving the $\pm 45^{\circ}$ plies outside the sequence (cf. the $[45 /-45 / 90 / 0]_{\mathrm{s}}$-sequence column) lead to an increase of the critical load in comparison to the $[90 / 45 /-45 / 0]_{\mathrm{s}}$ sequence by ca. $25 \%$.

Post-critical equilibrium paths were also determined for the nodes experiencing maximal

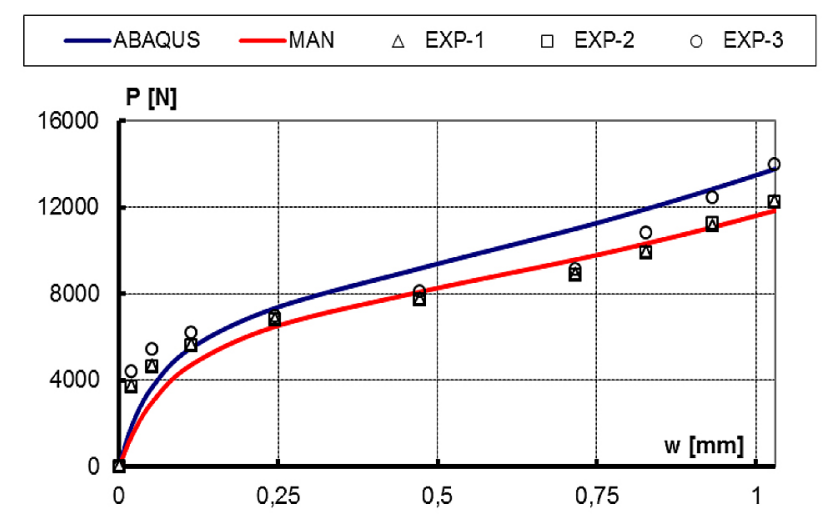

Fig.13. Comparison of post-buckling paths obtained numerically with experimental results for the $[45 /-45 / 90 / 0]_{s}$-sequence column 
amplitudes of displacement in a slightly postcritical state. Figures 12 and 13 present the results of experiments, as well as the FEM and the ANM method results in dimensional coordinate system $(P-w)$. The presented characteristics exhibit high conformity of the obtained results for all the exploited research methods. The maximal quantitative differences were obtained for the $[90 / 45 /-45 / 0]_{s}$-sequence column at a level of $18 \%$ and in case of the $[45 /-45 / 90 / 0]_{\mathrm{s}}$-sequence column - $14 \%$ (ANM/ABAQUS).

The analysis of the post-cricital equilibrium path allows to assess the structure stiffness after the loss of stability in the context of applied ply sequence. In both cases within the postcritical range up to $150 \%$ of the critical load, similar stiffness of the tested structures was observed, which was reflected by close inclination angles of both characteristics. The comparison of the postcritical equilibrium paths in function of the composite ply sequence for the FEM and the ANM calculations, as well as the experimental outcomes is presented in Figures 15 - 17.

\section{CONCLUSIONS}

The paper presents the studies on critical, as well as post-critical state of thin-walled composite columns subjected to axial compression. The performed analysis proved qualitative and quantitative agreement of the research results conducted with different methods. The analysis of the curves showed in Fig. 12 and 13 reveals a good agreement of computational results with those of experiments, both in subcritical and postcritical range. This confirms the adequacy of the worked out numerical models. The postcritical equilibrium paths determined with the analyticalnumerical method (ANM) exhibit slightly lesser a)
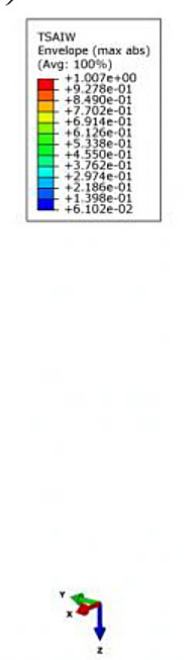

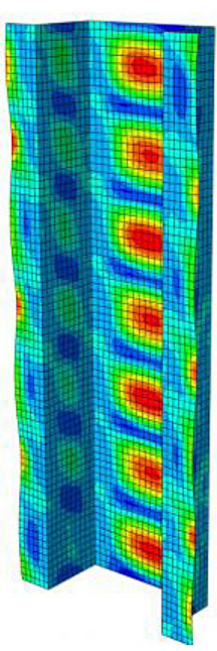

b)

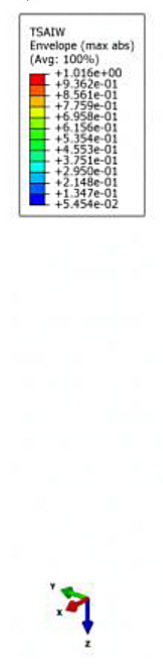

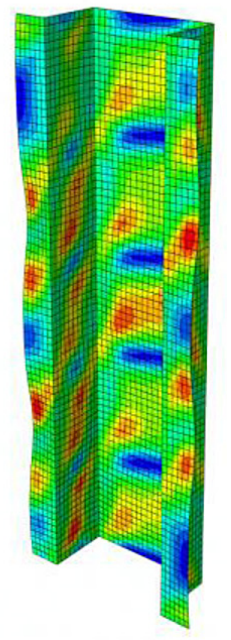

Fig. 14. Post-critical deformation state (Tsai-Wu criterion): a) $[90 / 45 /-45 / 0]_{\mathrm{s}}$, b) shup $[45 /-45 / 90 / 0]_{\mathrm{s}}$

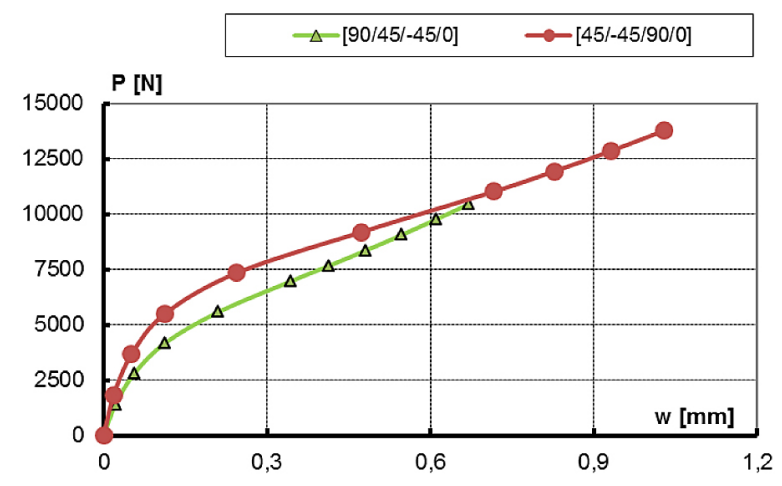

Fig. 15. Comparison of postcritical equilibrium paths - FEM results 


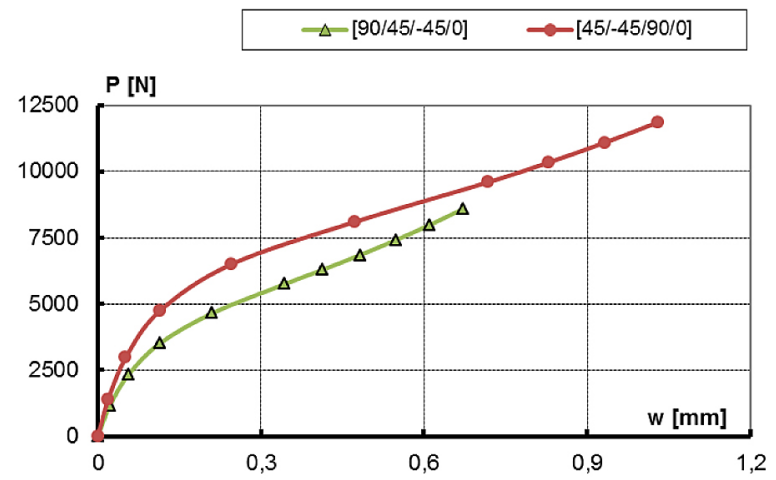

Fig. 16. Comparison of postcritical equilibrium paths - ANM results

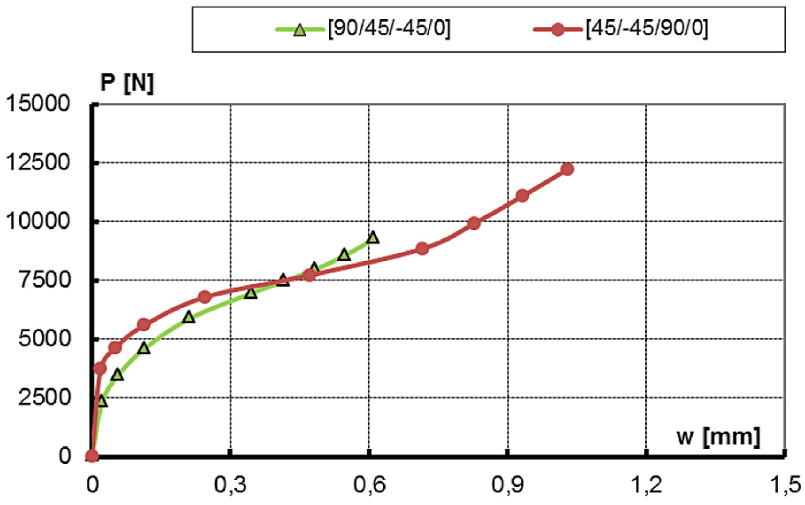

Fig. 17. Comparison of postcritical equilibrium paths - experimantal results

stiffness in comparison with the numerical (FEM) results. Moreover, one can spot that the experimental results shown in Figures 12 and 13 are located between the postritical equilibrium paths determined with the ANM and the FEM methods. It allows to verify advantageously calculation results in relation to the characteristics of the real structures.

The comparison of the results within a context of the applied ply sequence exhibits a considerable increase of the critical load's value through location of the $\pm 45^{\circ}$ plies outside, having kept the geometrical and material parameters of the structure. Thus, the obtained results delivered a lot of important information, useful in the process of forming and optimization of the composite texture in the context of its maintenance loading conditions [23].

\section{Acknowledgements:}

The research has been conducted under the project No. UMO-2015/19/B/ST8/02800 financed by the National Science Centre Poland.

\section{REFERENCES}

1. Campbell F.C., Manufacturing Technology for Aerospace Structural Materials. Elsevier, 2006.

2. Miracle, D.P., Donaldson, S.L. (eds), ASM Handbook Vol. 21 Composites. ASM International, 2001.

3. Freeman, W.T., The Use of Composites in Aircraft Primary Structure. Composites Engineering, Vol. 3, Nos 7-8, pp. 767-775, 1993.

4. Swanson S.R., Introduction to Design and Analysis with Advanced Composite Materials. PrenticeHall, Inc.,1997.

5. H.Dębski, J.Jonak: Failure analysis of thin-walled composite channel section columns, Composite Structures 132 (2015) 567-574.

6. Wysmulski P., Debski H., Rozylo P., Falkowicz K. A study of stability and post-critical behaviour of thin-walled composite profiles under compression,Eksploatacja i Niezawodnosc- Maintenance and Reliability, 18(4): pp. 632-637, 2016.

7. Kopecki T., Mazurek P., Lis T., Chodorowska D., Post-buckling deformation states of semi-monocoque cylindrical structures with large cut-outs under operating load conditions. numerical analysis 
and experimental tests, Eksploatacja i Niezawodnosc-Maintenance and Reliability 18(1): pp. 16-24, 2016.

8. Rozylo P., Teter A., Debski H., Wysmulski P., Falkowicz K. Experimental and Numerical Study of the Buckling of Composite Profiles with Open Cross Section under Axial Compression, Applied Composite Materials 24: pp. 1251-1264, 2017.

9. Kopecki T., Mazurek P., Determination of stress distribution patterns in post-critical deformation states of thin-walled skins subjected to operating loads, Eksploatacja i Niezawodnosc-Maintenance and Reliability 16(1), pp. 608-615, 2014.

10. Koiter W.T., Elastic stability and post-buckling behavior. In:Proceedings of the Symposium on Non-linear Problems, Univ. of Wisconsin Press, Wisconsin, pp. 257-275, 1963.

11. Singer J, Arbocz J, Weller T., Buckling experiments. Experimental methods in buckling of thinwalled structure. New York: John Wiley \& Sons Inc.; Basic concepts, columns, beams, and plates, vol. 1; 1998. Shells built-up structures, composites and additional topics, vol. 2, 2002.

12. Coan JM., Large-deflection theory for plates with small initial curvature loaded in edge compression. SME, J Appl Mech,18, pp. 143-51, 1951.

13. Venkataramaiah KR, Roorda J., Analysis of local plate buckling experimental data. In: Sixth international specialty conference on cold-formed steel structures; 1982 November 16-17; St. Louis, Missouri, Missouri S\&T [formerly the University of Missouri - Rolla, pp. 45-74], 1982.

14. Tereszkowski Z., An experimental method for de- termining critical loads of plates. Arch Mech Eng, 3, pp. 485-93, 1970.

15. van der Heijden AMA, editor, W.T. Koiter's elastic stability of solids and structures. Cambridge University Press, 2009.

16. Bronshtein J.N, Semendyayev K.A., Guide Book to Mathematics. Zürich, Part6: Interpretation of Experimental Results. 1973.

17. Spencer H.H., Walker A.C., Technique for Measuring The Critical Loads of Columns and Plates.Paper No.2290A SESA Spring Meet-ing, 1974.

18. Kolakowski Z., Kowal-Michalska K. (eds.), Selected problems of instabilities in composite structures. A Series of Monographs, Technical University of Lodz, 1999.

19. Tsai SW, Wu EM., A general theory of strength for anisotropic materials. J. Compos. Mater. pp. 58-80,1971.

20. Thompson J.M.T., Hunt G.W., General theory of elastic stability. Wiley, New York, 1973.

21. Dębski H., Kubiak T., Teter A., Buckling and postbuckling behavior of thin-walled composite channel section beam. Composite Structures, 100,195-204, 2013.

22. Dębski H., Experimental investigation post-buckling behaviour of composite column with top-hat cross section. Eksploatacja i Niezawodność Maintenance and Reliability, Warszawa No2/2013, 105-109, 2013.

23. Bieniaś J., Dębski H., Surowska B., Sadowski T., Analysis of microstructure damage in carbon/epoxy composites using FEM. Computational Materials Science, 64, 168-172, 2012. 